Purdue University

Purdue e-Pubs

School of Materials Engineering Faculty

Publications

$9-27-2018$

\title{
Synthesis and Characterization of Polymer-Silica Composite Hydrogel Particles and Influence of Hydrogel Composition on Cement Paste Microstructure
}

Matthew J. Krafcik

B Bose

Kendra Erk

Follow this and additional works at: https://docs.lib.purdue.edu/msepubs

Part of the Materials Science and Engineering Commons

This document has been made available through Purdue e-Pubs, a service of the Purdue University Libraries.

Please contact epubs@purdue.edu for additional information. 
Manuscript received December 11, 2017; accepted for publication March 19, 2018; published online September 27, 2018.

1 School of Materials Engineering, Purdue University, 701 West Stadium Ave., West Lafayette, IN 47907, USA

2 School of Materials Engineering, Purdue University, 701 West Stadium Ave., West Lafayette, IN 47907, USA (Corresponding author), e-mail: erk@purdue.edu, (i) https://orcid.org/0000-00019238-1928
Matthew J. Krafcik, ${ }^{1}$ Baishakhi Bose, ${ }^{1}$ and Kendra A. Erk ${ }^{2}$

\section{Synthesis and Characterization of Polymer-Silica Composite Hydrogel Particles and Influence of Hydrogel Composition on Cement Paste Microstructure}

\section{Reference}

Krafcik, M. J., Bose, B., and Erk, K. A., "Synthesis and Characterization of Polymer-Silica Composite Hydrogel Particles and Influence of Hydrogel Composition on Cement Paste Microstructure," Advances in Civil Engineering Materials, Vol. 7, No. 4, 2018, pp. 590-613, https://doi.org/10.1520/ACEM20170144. ISSN 2379-1357

\section{ABSTRACT}

The objective of this research is to define the fundamental structure-property relationships of water-swollen polymer hydrogel particles that are employed as internal curing agents in cementitious mixtures, in addition to reporting a novel synthesis procedure for combining pozzolanic materials with hydrogel particles. Solution polymerization was performed to incorporate amorphous nanosilica particles within acrylic-based polymer hydrogel particles of varying chemical compositions (i.e., monomer ratio of acrylic acid (AA) to acrylamide (AM)). Experiments were designed to measure the absorption capacity and kinetics of hydrogel particles immersed in pure water and cementitious pore solution, as well as determine the impact of particles on cement paste microstructure. While majority-AM hydrogel particles displayed relatively stable absorption values during immersion in pore solution, majority-AA hydrogel particles desorbed fluid over time, most likely due to the interactions of multivalent cations in the absorbed solution with the anionic polymer network. Interestingly, the addition of negatively charged nanosilica particles accelerated and enhanced this desorption response. When incorporated into cement paste, majority-AM hydrogel particles encouraged the formation of calcium hydroxide and calcium silicate hydrate within the void space previously occupied by the swollen particles. When nanosilica was added to the 
hydrogel particles, a $53 \%$ increase in the number of hydrogel voids containing hydrated product was observed for the $17 \%$ AA hydrogel particles, and a $140 \%$ increase was observed for the $83 \%$ AA hydrogel particles. These results suggest that the combination of nanosilica with polymeric hydrogel particles provides a favorable environment for the pozzolanic reaction to proceed and that nanosilica aids in the replenishment of hydrogel void space with hydrated cement phases.

\section{Keywords}

hydrogel particles, nanosilica, internal curing, high-performance concrete, microstructure, chemical admixtures, superabsorbent polymer

\section{Introduction}

High-performance concrete (HPC) has a very dense microstructure compared to conventional concretes, due in part to a significantly reduced water-to-cement $(w / c)$ ratio [1], such that all the water in the mixture is consumed during the hydration reaction [2]. The dense microstructure produces a strong and durable structure with a reduced impact on the environment $[3,4]$. The main technical challenge of using HPC is the autogenous shrinkage that is encountered during the early stages of curing, eventually resulting in the formation of cracks, increased porosity, and an overall reduction in strength [5-7].

Conventional external curing methods used in the construction industry cannot fully mitigate autogenous shrinkage, as the dense microstructure of HPC limits the penetration of water [8]. Hence, internal curing of HPC provides additional water for hydration reactions from within the concrete $[9,10]$ and consequently reduces shrinkage [11-13]. Superabsorbent polymer hydrogel particles provide an effective method of internal curing [14-17], because the hydrogel particles can absorb and release large amounts of water to fuel the hydration reaction [13]. The use of hydrogel particles for internal curing has been found to reduce autogenous shrinkage [17-24], reduce crack propagation $[9,25,26]$, increase autogenous sealing potential $[9,27,28]$, increase resistance to freeze-thaw cycles [29-34], and increase durability [33,35,36].

Pozzolanic materials (e.g., silica fume (SF), fly ash, etc.) are widely used in the production of HPC [21,37-41]. With the advent of nanotechnology, various forms of amorphous nanosilica with high specific surface have been used, as they have been observed to have higher pozzolanic activity than conventional SF $[42,43]$. The combination of a pozzolan with internal curing has been attempted in the past through porous rice husk ash and expanded shale $[44,45]$. In those cases, a porous material with inherently pozzolanic properties (i.e., a high proportion of amorphous silica phases) was presoaked in water and used as a replacement for either the cement or fine aggregate. Polyacrylate-based hydrogels containing fly ash have been synthesized for use in enhanced oil recovery [46], and hydrogels containing rice-husk ash have been used in soil conditioning [10,47], but, to our knowledge, the incorporation of nanosilica directly within a hydrogel particle for use in internally cured, cement-based materials has not been previously attempted.

In this article, we present a novel approach for combining nanosilica $\left(\mathrm{SiO}_{2}\right)$ particles with a polymeric internal curing agent (hydrogel) through a facile synthesis procedure. To better understand the effect of including nanosilica within the hydrogel particles, four different compositions of poly(acrylic acid (AA)-acrylamide (AM)) hydrogel particles were synthesized and will be referred to by their weight percentage of the monomer 
AA only: $17 \% \mathrm{AA}, 83 \% \mathrm{AA}, 17 \% \mathrm{AA}+\mathrm{SiO}_{2}$, and $83 \% \mathrm{AA}+\mathrm{SiO}_{2}$. For compositions which contain nanosilica, the dosage was fixed at $8.5 \% \mathrm{SiO}_{2}$ by weight of monomer. To evaluate the performance of these hydrogel particles, gravimetric swelling tests in reverse osmosis (RO) water and cement pore solution were conducted. Additionally, the hydrogel particles were incorporated into cement pastes, and backscattered electron microscopy was performed to directly quantify the effect of hydrogel addition on paste void structure and hydrated phase formation.

\section{Background}

Superabsorbent polymer (hydrogel) particles are chemically crosslinked polymer networks, usually composed of AA and AM segments. A simplified schematic of a swollen hydrogel-silica network is shown in Fig. 1, and a scanning electron microscope image of dry hydrogel particles is shown in Fig. 2. Hydrogel particles can absorb up to 1,500 times their dry weight in water [48] and can be used in place of traditional lightweight aggregate (LWA) for internal curing. Hydrogel particles have several advantages over LWA in that they require no presoaking and can be added in very small amounts to cementitious mixtures (e.g., $0.2 \%$ by weight of cement) while still providing effective internal curing $[1,49,50]$. Although hydrogel particles are mechanically weaker than LWA, the direct impact that hydrogel particles have on the compressive strength of mortar and concrete is still unclear. Some researchers have reported that hydrogel particles can either increase or decrease the compressive strength of mortar depending on dosage [51], while others have reported that hydrogel particles caused a decrease in early-age strength that recovered with time $[17,52]$. Our previous research called attention to the fact that hydrogel shape and chemistry can significantly influence the compressive strength of mortar [53,54].

In contrast to most LWA, however, hydrogel particles are not chemically inert within cementitious mixtures. In the case of hydrogel particles containing AA, the carboxylic acid functional groups undergo deprotonation in alkaline conditions (as the $\mathrm{pKa}$ of $\mathrm{AA}$ is

\section{FIG. 1}

A schematic representation of nanosilica particles confined within a water-swollen polymer network (i.e., a relatively small region of a hydrogel particle). AA and AM portions of the network are indicated with arrows and the network is represented as alternating block polymer of AA and AM (monomer chemistries are included). MBAM, the covalent crosslinker, is indicated with small squares, and the polymer network is drawn to demonstrate that crosslinking density may not be uniform throughout the entire hydrogel particle.

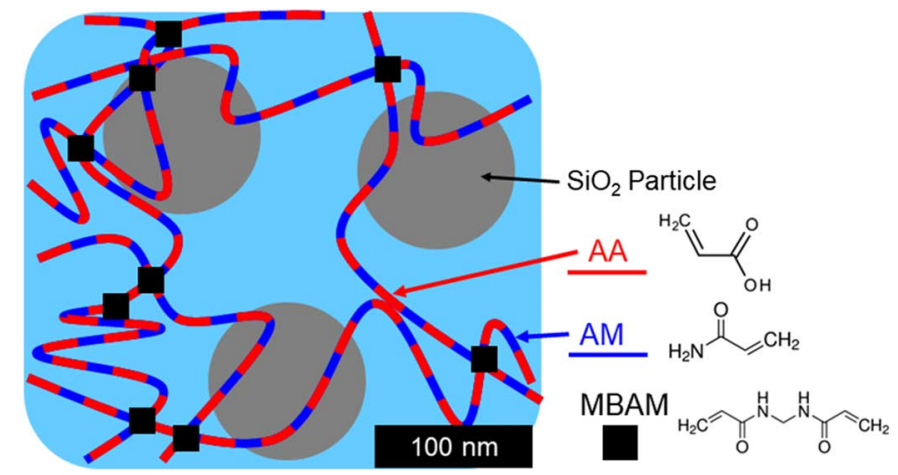


FIG. 2

Scanning electron microscope image of dry $17 \% \mathrm{AA}+\mathrm{SiO}_{2}$ hydrogel particles.

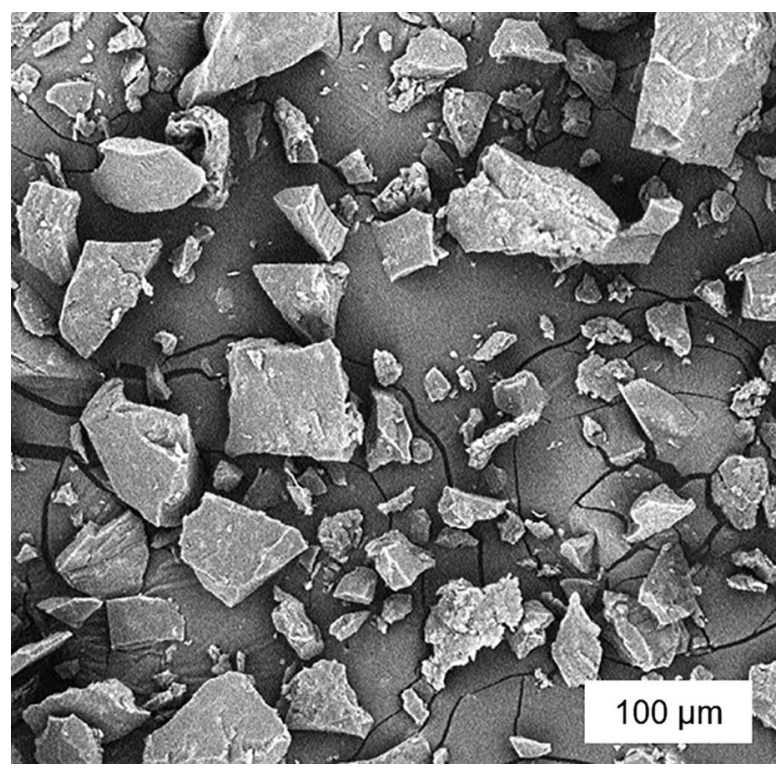

approximately $4.5[55])$, forming anionic carboxylate $\left(\mathrm{COO}^{-}\right)$moieties in the polymer network and allowing significant amounts of water to be absorbed by virtue of ion-dipole interactions [56-59]. For these charged polymer networks, the primary mechanism of hydrogel swelling can be attributed to the creation of a chemical potential gradient across the hydrogel-fluid interface, as the anionic polymer network results in a higher concentration of free counterions within the hydrogel particle compared to the surrounding fluid in order to preserve electroneutrality within the system [60]. This gradient creates an osmotic pressure which drives the diffusion of water into the hydrogel particle along with other ions in solution, and the particle will continue to swell until the net osmotic pressure is reduced to zero. Cations present in the aqueous fluid (including sodium, calcium, and aluminum ions) will be electrostatically attracted to the $\mathrm{COO}^{-}$moieties and form ionic complexes that effectively act as crosslinks within the polymer network, the formation of which decreases the equilibrium absorption capacity of the hydrogel $[56,61]$ and can ultimately lead to the collapse of the polymer network, as we recently demonstrated [57]. In the concrete materials community, there is a growing body of research to accurately quantify the absorption and desorption behavior of hydrogel particles in cementitious pore solutions, as certain hydrogel compositions (including commercially available products) have been found to display strong sensitivity to the mono- and multivalent cations that are naturally present in pore solutions depending on mixture age [17,57,62-66].

In addition to changes in swelling performance, hydrogel particles used as internal curing agents have also been found to impact the inorganic chemistry of cement, specifically the development of calcium hydroxide $(\mathrm{CH})$ and calcium-silicate-hydrate $(\mathrm{CSH})$ phases [24]. Recent findings by our research group [57] suggested that hydrogel particles composed mainly of polyacrylamide were able to form significant amounts of $\mathrm{CH}$ phases within the hydrogel void space. Thus, the incorporation of a pozzolanic material within the hydrogel network may form an additional CSH phase, perhaps leading to a further increase in the mechanical properties and durability of internally cured concrete. 
The use of pozzolanic materials in HPC has long been a common practice [67], and the benefits of using pozzolanic supplementary cementitious materials (SCMs) are numerous. They have been found to enhance the impermeability, strength, durability, and increase resistance to crack propagation in concrete [68,69]. Although many types of SCM have been studied, the rate of the pozzolanic reactions and thus the enhancement properties of the hardened cement paste vary with different SCMs [70,71]. A widely used pozzolanic SCM is SF, which is a waste product of the ferro-silicon industry [72] and is composed of spherical particles ranging from hundreds of nanometers to tens of microns in size. SF is almost entirely amorphous $\mathrm{SiO}_{2}$ and is a pozzolan, which indicates that it will react with water and $\mathrm{CH}$ to form $\mathrm{CSH}[73,74]$.

SF can be added as a partial replacement for ordinary portland cement (OPC) and is known to provide substantial benefits to the system. As a replacement for OPC, SF helps to reduce the cost and carbon footprint associated with concrete consumption [41,72-75]. The use of SF has also been shown to increase the durability of concrete structures by aiding in the hydration of CSH phases as well as lowering total porosity and refining the porosity immediately surrounding aggregates [75,76]. Since SF consumes the $\mathrm{CH}$ phase, concrete-containing SF has been shown to be more resistant to sulfate attacks [72,73]. SF is also used in order to provide an increase in the compressive strength of concrete $[41,72-74,77]$.

For all of its positive effects, the use of SF is not without some disadvantages. Depending on particle size and surface area, SF can substantially reduce the consistency of a concrete mix [72,76,78,79], and thus, the use of water reducing admixtures (WRA) or superplasticizers are necessary. SF has been shown to increase setting times, and the effect is exacerbated when SF is used in conjunction with a WRA [41,78]. The dispersion and replacement level of SF are also important variables, as too high a replacement of cement with SF or agglomerated SF particles can cause a decrease in compressive strength [79]. SF has also been shown to increase autogenous shrinkage [77], which necessitates the use of internal curing.

With progress in nanotechnology research, previous studies have effectively used nanoscale SF particles to improve the performance of cement-based materials [80]. Zeta potential has been used to give an indication of the surface charge state of particles and aid in the understanding of both particle-particle interactions and polymer-particle interactions in cement mixtures [81]. The zeta potential is a measurement of the electric potential at the slipping plane surrounding a particle (or molecule) suspended in solution [82]. Researchers have shown that over a wide range of $\mathrm{pH}$ (neutral to alkaline), the nanosilica particles are negatively charged [83,84]. Nanosilica is an attractive SCM as it has been found to improve both the strength and microstructural properties of cement [85-88]. A better performance of cement mixtures containing nanosilica has been observed in comparison to those with SF $[85,86]$. The extremely fine particle size of nanosilica may make it an inhalation hazard for workers, although amorphous silica has not been conclusively proven to cause pulmonary sicknesses, in contrast to the known toxicity of crystalline silica [89].

Our recent research [57] on hydrogel-ion interactions and influence of hydrogel chemistry on cement paste microstructure indicated that the chemical structure of hydrogel particles could be tuned to increase the amount of $\mathrm{CH}$ phases that forms within the hydrogel void. It is thus anticipated that the incorporation of nanosilica in these hydrogel particles will facilitate the formation of additional CSH within the void space, by taking advantage of the combination of a pozzolan and absorbed water within the hydrogel 
network. Additionally, by placing nanosilica $(<100 \mathrm{~nm})$ within much larger hydrogel particles (approximately $100 \mu \mathrm{m}$ ), we hope to overcome the dispersion and consistency issues caused by adding plain nanosilica directly into a cement mixture.

Because of the incorporation of amorphous silica into cement, care must be taken to ensure that an alkali-silica reaction (ASR) does not occur. ASR refers to the phenomenon wherein alkaline hydroxides in concrete pore solution react with amorphous silica phases in aggregates and produce detrimental volumetric expansion. The nanosilica used in this study is of a much smaller size than silica-rich aggregates. Also, the formation of CSH via the pozzolanic reaction has a low calcium oxide to silica ratio, which enables the entrapment of alkalis and depletion of $\mathrm{CH}$, and thus decreases the amount of hydroxyl ions available to participate in the ASR [90-92]. Thus, the nanosilica added to the hydrogel particles is effectively too small to cause ASR.

\section{Materials and Methods}

\section{HYDROGEL SYNTHESIS AND SIZING}

AA, AM, methylenebisacrylamide (MBAM), sodium metabisulfate $\left(\mathrm{NaS}_{2} \mathrm{O}_{5}\right)$, and sodium persulfate $\left(\mathrm{NaS}_{2} \mathrm{O}_{8}\right)$ were used as received and purchased from Sigma-Aldrich (St. Louis, $\mathrm{MO})$. Silica nanoparticles $\left(\mathrm{SiO}_{2}\right)$ were purchased from U.S. Research Nanomaterials, Inc. of Houston, TX (reported 60-70 nm diameter). Deionized (DI) water with a total dissolved solids content of less than 13 parts per million was collected from a Barnstead Nanopure Infinity system (Barnstead Thermolyne Corporation, Ramsey, MN).

Prior to hydrogel synthesis, fresh neutralization, crosslinking, and initiator solutions were prepared. A neutralization solution was prepared with $15.72 \mathrm{~g}$ of sodium hydroxide ( $\mathrm{NaOH}$, pellets from Mallinckrodt, Staines-upon-Thames, United Kingdom) in $40 \mathrm{~mL}$ of DI water (approximately $9.8 \mathrm{M}$ ) to neutralize AA to a sodium acrylate monomer. To ultimately achieve a crosslinking concentration within the hydrogel particles of $2 \%$ by weight of monomer, a batch solution of $0.3 \mathrm{~g}$ MBAM in $20 \mathrm{~mL}$ DI water was prepared. Initiator solutions of $\mathrm{NaS}_{2} \mathrm{O}_{5}$ and $\mathrm{NaS}_{2} \mathrm{O}_{8}$ (dosed at $1 \%$ by monomer weight) were separately mixed at $0.3 \mathrm{~g}$ in $10 \mathrm{~mL}$ DI water.

Reagent components are summarized in Table 1. The dosage of nanosilica was held constant at $8.5 \% \mathrm{SiO}_{2}$ by weight of monomer and the crosslinking of the hydrogel particles was $2 \%$ by weight of monomer. The hydrogel synthesis adapted from Zhu, Barney, and Erk [62] proceeded as follows. The gel reactions were conducted in capped $20 \mathrm{~mL}$ glass scintillation vials. $\mathrm{SiO}_{2}$ and water were added to the vials first. AA monomer (a liquid at room temperature) was added, and then the neutralization solution was added dropwise while stirring. Vials were allowed to cool for 5 minutes. AM monomer (a solid at room temperature) and $4 \mathrm{~mL}$ of MBAM batch solution were added and stirred for an additional

TABLE 1

Proportions of monomers and nanosilica for both hydrogel compositions evaluated in this study.

\begin{tabular}{lccccc}
\hline Sample & $\mathrm{SiO}_{2}, \mathrm{~g}$ & Water, $\mathrm{mL}$ & $\mathrm{AA}, \mathrm{mL}$ & $\mathrm{NaOH}$ Soln., mL & AM, g \\
\hline $17 \% \mathrm{AA}$ & 0 & 6.2 & 0.5 & 0.8 & 2.5 \\
$17 \% \mathrm{AA}+\mathrm{SiO}_{2}$ & 0.255 & 6.2 & 0.5 & 0.8 & 2.5 \\
$83 \% \mathrm{AA}$ & 0 & 3 & 2.5 & 4 & 0.5 \\
$83 \% \mathrm{AA}+\mathrm{SiO}_{2}$ & 0.255 & 3 & 2.5 & 4 & 0.5 \\
\hline
\end{tabular}


5 minutes. Initiator solutions were added at $0.5 \mathrm{~mL}$ each and vials were placed in a temperature-controlled oil bath set at $60^{\circ} \mathrm{C}$ until gelation was observed, which typically took between 1 and 8 hours.

Twelve hours after gelation, hydrogel particles were removed from the scintillation vials and "washed" by soaking in water for an additional 12 hours to remove any unreacted monomer. The hydrogel particles containing nanosilica were whiter (more opaque) in appearance than the hydrogel particles without nanosilica, suggesting that even in highly saturated, fully swollen conditions, the nanosilica particles remain confined within the polymer network. Indeed, during synthesis, washing, and all gravimetric swelling experiments, there was no visible evidence of $\mathrm{SiO}_{2}$ escaping from the hydrogel particles (e.g., no $\mathrm{SiO}_{2}$ aggregates were observed to sediment in the reaction vessels or beakers used for washing steps and gravimetric swelling tests). Work is currently being performed to more quantitatively measure the nanosilica concentration in hydrogel particles through thermal analysis techniques, as well as X-ray scattering measurements.

After the washing step, specimens were then dried in an oven at $80^{\circ} \mathrm{C}$ for 8 hours and ground into a fine powder using an electric coffee grinder. For each composition, a sample of dry hydrogel particles were placed onto a glass microscope slide, and images were taken at 100x magnification using an optical microscope. Enough pictures were collected to analyze the size of at least 100 particles, which were measured with ImageJ (National Institutes of Health, Bethesda, MD). Because of the angular shape of the hydrogel particles, only the maximum length (major axis) of each particle was reported in the results (see the "Physical Analysis of Hydrogel Particles" section).

Using the synthesis inputs reported in Table 1, a rough estimate of the average mass and volume loadings of nanosilica particles in dry and swollen hydrogel particles was determined. The following assumptions were required: the average density of the AA and AM monomers is $1.09 \mathrm{~g} / \mathrm{cm}^{3}$, and the density of nanosilica is $2.20 \mathrm{~g} / \mathrm{cm}^{3}$ [93]; an average dry hydrogel particle is cubic with $100 \mu \mathrm{m}$ dimensions (and thus a volume of $1 \times 10^{-6}$ $\mathrm{cm}^{3}$ ); and crosslinker mass and volume are negligible. Assuming the nanosilica particles were spherical with an average radius of $35 \mathrm{~nm}$ (as indicated by the manufacturer's specifications), the volume of each nanosilica particle was estimated to be $1.8 \times 10^{-16} \mathrm{~cm}^{3}$. Assuming that the synthesis reaction yields a total dry solid volume of approximately $3.2 \mathrm{~cm}^{3}$ (slightly inflated to take into consideration polymer-excluded volume [94]), then each dry hydrogel particle is estimated to contain $2.0 \times 10^{8} \mathrm{SiO}_{2}$ particles, or a concentration of $3.6 \%$ by volume. As the hydrogel particle swells with fluid, the $\mathrm{SiO}_{2}$ concentration will proportionally decrease; e.g., if the cubic hydrogel particle swells with fluid to reach $400 \mu \mathrm{m}$ dimensions $\left(6.4 \times 10^{-5} \mathrm{~cm}^{3}\right)$, then the concentration of $\mathrm{SiO}_{2}$ will decrease to $0.06 \%$ by volume.

It is important to note that $\mathrm{SiO}_{2}$ is most likely not uniformly distributed throughout each hydrogel particle, because of inhomogeneities in the polymer network (e.g., variation in crosslink density, see Fig. 1) as well as the potential settling of larger nanosilica aggregates during the hydrogel polymerization reaction. In current work, a suspension polymerization technique is being investigated to better control the reaction kinetics and ensure greater uniformity in $\mathrm{SiO}_{2}$ concentration and hydrogel particle shape and size. Given these limitations, the calculations described above do seem to indicate that in the cementitious environment, the estimated loading levels of $\mathrm{SiO}_{2}$ in the hydrogel particles are much less than one percent, which makes the observed changes in microstructure all the more impressive. 


\section{NANOSILICA PARTICLE CHARACTERIZATION}

$\mathrm{X}$-ray diffraction $(\mathrm{XRD})$ was performed on the nanosilica particles using a Siemens D500 diffractometer $(30 \mathrm{~mA}, 50 \mathrm{kV})$ at $0.02^{\circ} / \mathrm{s} \mathrm{scanning}$ rate in $(10-40)^{\circ} 2 \theta$ range (Siemens AG, Berlin and Munich, Germany). The specimen was prepared by loosely packing the nanosilica particles into a top-loaded metal sample holder pressed to a paper surface in order to avoid preferential orientation of the nanoparticles. A Nanosizer nano-z (Malvern Instruments, Malvern, United Kingdom) was used to measure the zeta potential of dilute suspensions of nanosilica particles dispersed in DI water. Two samples were created at different values of $\mathrm{pH}, 6.3 \pm 0.1$ and $12.4 \pm 0.1$, through the progressive addition of a $2 \mathrm{M} \mathrm{NaOH}$ solution, and measured with an electronic $\mathrm{pH}$ meter. Nanoparticles were added to the solution at a concentration of $30 \mathrm{~g} / \mathrm{ml}$ (1 wt.\%), stirred, and allowed to equilibrate at $25^{\circ} \mathrm{C}$ for 2 hours prior to testing. During this time, larger particle aggregates were observed to sediment out of the solution, leaving only a suspension of dispersed isolated particles and smaller aggregates (less than a few microns in size) within the suspension, which was subsequently analyzed. Three measurements were performed for each sample and averaged.

\section{CEMENT PASTE BATCHING}

For pastes, Type I OPC (ASTM C150, Standard Specification for Portland Cement) [95] obtained from Buzzi Unicem (Greencastle, IN, USA) was used. The Blaine fineness was reported to be $377 \mathrm{~m}^{2} / \mathrm{kg}$, loss on ignition was $1.34 \mathrm{wt} . \%$, and the oxide weight percentages are as follows: $20.04 \% \mathrm{SiO}_{2}, 4.85 \%$ aluminum oxide, $3.35 \%$ iron(III) oxide, $63.5 \%$ calcium oxide, and $1.99 \%$ magnesium oxide. All percentages were obtained from the manufacturer's mill certificate. Mixture proportions are listed in Table 2. Tap water that had been tempered to room temperature was used for mixing, and Glenium 3030 NS full-range WRA, supplied by BASF (Ludwigshafen, Germany), was used as the superplasticizer. The hydrogel dosage (dry weight) was fixed at $0.2 \%$ by weight of cement. This is equivalent to $0.57 \%$ by volume of dry cement.

A Renfert Twister Evolution vacuum mixer (Renfert, Hilzingen, Germany) was used to mix all pastes to ensure that any porosity would be due to capillary water and hydrogel particles. The mixture proportions for the paste samples are given in Table 2. Dry cement that had been mixed with dry hydrogel particles (if applicable) was added to a cup. Water and WRA were added simultaneously, and the cup was placed onto the mixer. A vacuum was pulled, and the materials were mixed for 60 seconds. After the first mixing period, the cup was removed, its sides scraped with a spoon, and left to sit for 45 seconds. Finally, the cup was reattached to the mixer and mixed for an additional 60 seconds under vacuum. The paste was then poured directly into a plastic mold, sealed, and placed in an environment chamber at $(25 \pm 1)^{\circ} \mathrm{C}$ and $(50 \pm 1) \%$ relative humidity for 24 hours before being

TABLE 2

Mixture proportions for pastes with and without hydrogel particles. Hydrogel dosage, WRA dosage, and total water contents are fixed across all samples. WRA is percent by weight of cement.

\begin{tabular}{lcccc}
\hline Sample & Cement, g & Water, g & Hydrogel Particles, g & WRA, \% \\
\hline Control & 200 & 70 & - & 0.7 \\
$17 \% \mathrm{AA}$ & 200 & 70 & 0.4 & 0.7 \\
$17 \% \mathrm{AA}+\mathrm{SiO}_{2}$ & 200 & 70 & 0.4 & 0.7 \\
$83 \% \mathrm{AA}$ & 200 & 70 & 0.4 & 0.7 \\
$83 \% \mathrm{AA}+\mathrm{SiO}_{2}$ & 200 & 70 & 0.4 & 0.7 \\
\hline
\end{tabular}


removed from their containers and placed into saturated limewater solutions for 48 additional hours. Samples were weighed before and after being removed from the plastic containers to ensure no mass loss had occurred in the first 24 hours.

\section{GRAVIMETRIC SWELLING TESTS OF HYDROGEL PARTICLES}

Hydrogel swelling capacities and kinetics were evaluated in RO water with a total dissolved solids of approximately 18 and cement pore solution. The pore solution was prepared by mixing cement directly with tap water at a w/c ratio of 10 and stirring for 30 seconds. The mixture was allowed to settle for another 30 seconds, after which the topmost portion was decanted into a separate beaker. This portion was immediately covered to prevent carbonation and used for gravimetric swelling tests.

The gravimetric "teabag" method was used to determine the transient absorption response of the hydrogel samples used in this study, following past protocols [57,63]. For both solutions, $200 \mathrm{ml}$ of liquid was added to a beaker, and a teabag was fully immersed into the solution for 30 seconds. The teabag was allowed to drip dry and then weighed to obtain the wet mass of the bag, $m_{\text {bag }}$. A mass of $0.2 \mathrm{~g}$ of dry hydrogel particles, $m_{d r y}$, were added to the wet teabag. The teabag was then immersed into solution and removed at the following time intervals for weighing to obtain $m_{\text {wet }}: 1,3,5,10,15,30,60$, 120 , and 240 minutes. In the case of the pore solution, the beakers were covered in between weighing intervals to minimize the risk of carbonation. Tests were repeated in triplicate to obtain the average and standard deviation. The gravimetric swelling ratio $(Q)$ in units of grams of absorbed fluid per grams of dry hydrogel was calculated using the following formula:

$$
Q=\frac{m_{w e t}-m_{b a g}-m_{d r y}}{m_{d r y}}
$$

After freshly synthesized hydrogel particles were swollen for 4 hours (one test) in RO water, they were removed from the teabags, spread out on watch glasses, and dried overnight in an oven at $85^{\circ} \mathrm{C}$. The same hydrogel particles were then added to new teabags and subjected to another swelling test in a beaker of fresh $\mathrm{RO}$ water to obtain reswelling data.

\section{BACKSCATTERED ELECTRON MICROSCOPY}

Vacuum-mixed paste samples were used for all electron microscopy imaging. Cured cylinders were cut into small pieces with a saw, vacuum dried at $(60 \pm 5)^{\circ} \mathrm{C}$ for 72 hours, and vacuum-impregnated with a low-viscosity epoxy that was cured overnight at the same temperature. The sample preparation method did cause slight macroscopic cracking as a result of drying shrinkage, and there may have been some decomposition of ettringite phases during the curing of the epoxy. These possible changes to microstructure were unavoidable, since the presence of any free water and temperatures less than $60^{\circ} \mathrm{C}$ prevents successful curing of the epoxy.

A fresh section of each epoxy specimen was exposed with a diamond saw, and the section was then polished with $3 \mu \mathrm{m}, 1 \mu \mathrm{m}$, and $0.25 \mu \mathrm{m}$ polycrystalline diamond suspension. All samples were carbon coated. Backscattered electron images at a minimum magnification of 250x and elemental analysis from X-rays (EDX) were obtained with a NanoScience Instruments Phenom Desktop SEM (Phoenix, AZ). For elemental analysis, point mapping with a $15-\mathrm{kV}$ accelerating voltage was used. From repeated measurements of cement phases with known compositions, it was determined that the quantitative 
analysis uncertainty is (3-5) weight percent. To obtain the percentage of voids containing phases, pictures were taken of the entire sample surface, and at least 100 voids from each sample were analyzed.

\section{Results}

\section{PHYSICAL ANALYSIS OF HYDROGEL PARTICLES}

The zeta potential of the isolated nanosilica particles dispersed within two different aqueous environments was measured to be $-34.9 \mathrm{mV} \pm 0.8 \mathrm{mV}$ at $\mathrm{pH} 6.3$ and $-43.8 \mathrm{mV}$ $\pm 2.3 \mathrm{mV}$ at $\mathrm{pH} 12.4$. These results closely match those reported in literature $[83,84]$ and strongly suggest that the amorphous nanosilica particles have a negative surface charge over the alkaline range of $\mathrm{pH}$ that is most relevant for application in cementitious mixtures, including the environments explored in the present work.

The nanosilica was also examined with backscattered electron microscopy. As shown in Fig. 3a, a considerable variation in particle size was observed, including small particles on the order of hundreds of nanometers that appear as white specks and larger particles approximately (5-10) $\mu \mathrm{m}$ in size, most likely aggregates of individual nanosilica particles. The XRD results, shown in Fig. 3b, indicated that the nanosilica was highly amorphous. This was inferred from the extremely low overall intensity of the signal in addition to the very broad reflex, centered at about $22^{\circ}$. Had the nanosilica been crystalline, the pattern would have resembled that of quartz, with two high-intensity peaks about the $2 \theta$ of $20.8^{\circ}$ and $26.6^{\circ}$ [96]. While it is expected that the largest nanosilica aggregates break apart during hydrogel synthesis (which requires mixing), experiments are currently being performed to investigate the use of sonication to disrupt large aggregates of nanosilica particles prior to their incorporation into the hydrogel.

Size distributions of all the hydrogel compositions are shown in Fig. 4. As shown in Fig. 4a, for the $17 \%$ AA hydrogel particles that did not contain $\mathrm{SiO}_{2}, 96 \%$ of the particles

FIG. 3 (a) A backscattered electron image of nanosilica particles, displaying isolated particles as well as large particle aggregates; and (b) XRD pattern of nanosilica particles.

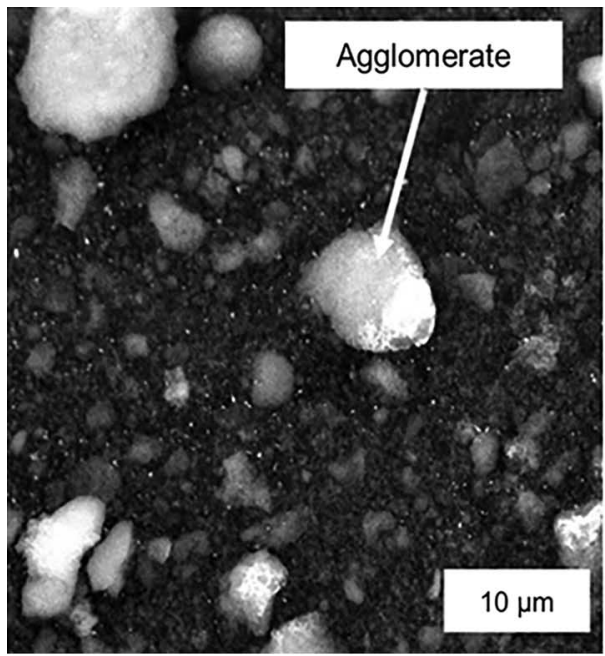

(a)

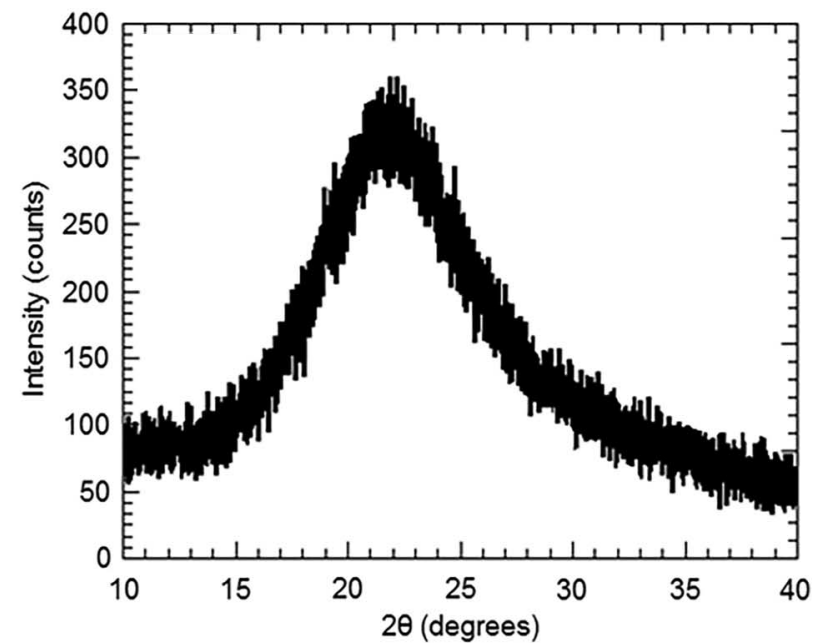

(b) 
FIG. 4 Hydrogel particle size distributions for all compositions: (a) $17 \% \mathrm{AA}$, (b) $83 \% \mathrm{AA}$, (c) $17 \% \mathrm{AA}+\mathrm{SiO}_{2}$, and (d) $83 \% \mathrm{AA}+\mathrm{SiO}$. The last bin contains all particles that are greater than $450 \mu \mathrm{m}$, which amounts to less than $6 \%$ of all counted particles in each sample.

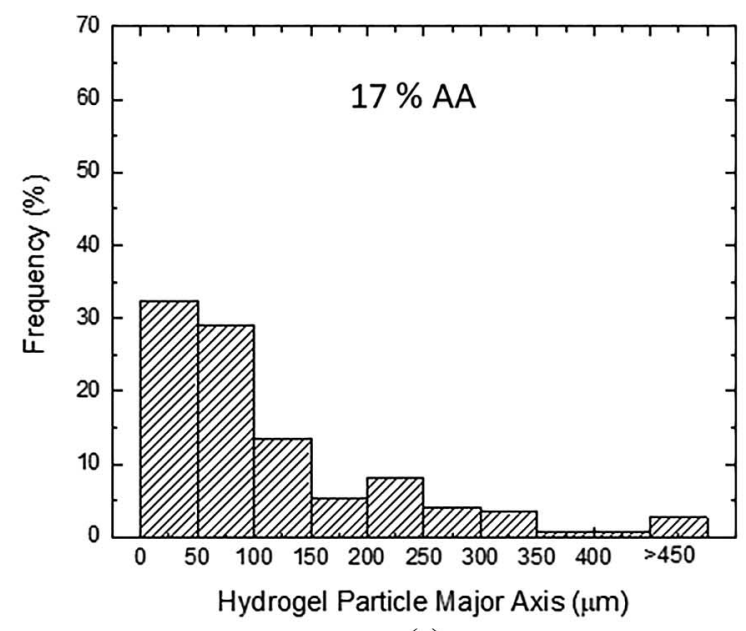

(a)

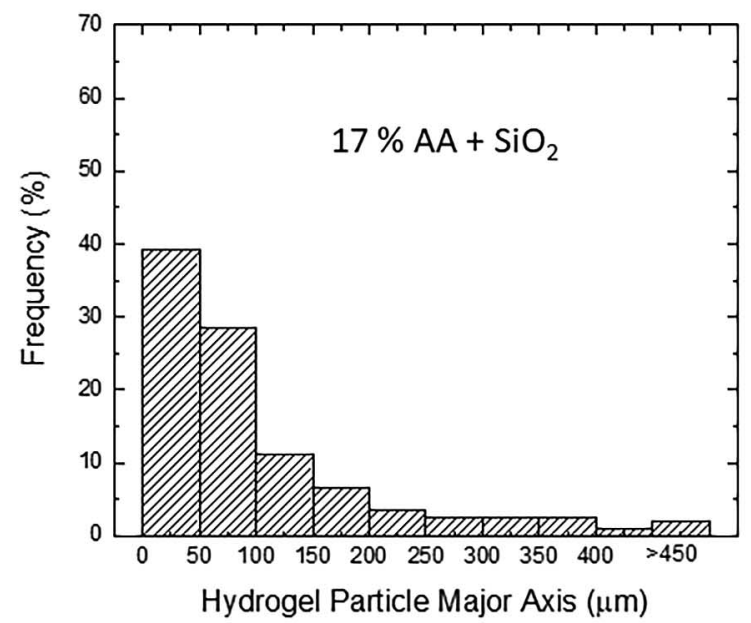

(c)

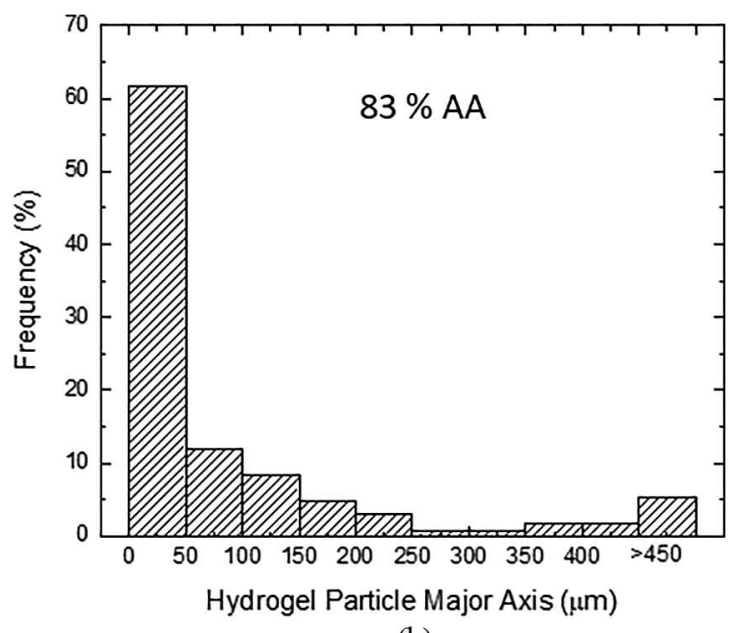

(b)

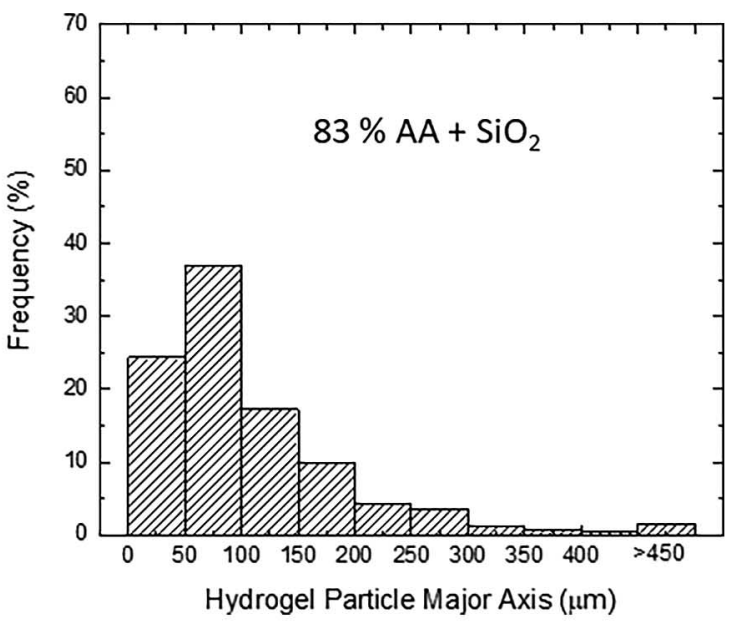

(d) 
desorption. To further reduce the size of hydrogel particles, additional mechanical grinding and cryomilling procedures can be utilized, the latter of which can be used to obtain relatively small hydrogel particles on the order of tens of microns in size [64]. A potential downside of incorporating such small hydrogel particles into a fresh cementitious mixture is the possible loss of paste workability, due to an increase in apparent yield stress and plastic viscosity from their increased absorption rate compared to larger particles [97].

\section{GRAVIMETRIC SWELLING TESTS OF HYDROGEL PARTICLES}

Gravimetric swelling tests were performed in order to understand the effect of nanosilica addition on the swelling kinetics and capacity of both hydrogel compositions examined in this study. These results are shown in Fig. 5. In RO water (see Fig. 5a), the 17 \% AA hydrogel particles reached an equilibrium swelling capacity within one minute of immersion, whereas the $83 \%$ AA did not reach an equilibrium swelling capacity until approximately one hour. The $17 \% \mathrm{AA}$ with $\mathrm{SiO}_{2}$ hydrogel particles displayed similar swelling behavior to the $83 \% \mathrm{AA}+\mathrm{SiO}_{2}$ hydrogel particles in that both compositions took approximately one hour to reach an equilibrium swelling capacity. The $17 \%$ AA hydrogel particles had markedly lower maximum swelling capacities (approximately 60 ) than the $83 \%$ AA hydrogel particles, which had a maximum swelling capacity of approximately 80 .

The addition of nanosilica did not significantly change the maximum swelling capacity or swelling kinetics of the $83 \%$ AA hydrogel, as indicated in Fig. 5 a. However, the $17 \%$ $\mathrm{AA}+\mathrm{SiO}_{2}$ hydrogel displayed a notably lower maximum swelling capacity of approximately 45. The swelling results for the hydrogel particles immersed in pore solution are shown in Fig. 5b. The addition of nanosilica did not appreciably change the swelling kinetics or capacity of the $17 \%$ AA hydrogel particles, and both reached an approximately equivalent swelling ratio of 19 within 10 minutes of immersion. The $83 \% \mathrm{AA}+\mathrm{SiO}_{2}$ hydrogel particles displayed significantly different swelling behavior in pore solution (see Fig. 5b). 83 \% AA reached a peak swelling capacity of approximately 30 at 5 minutes, and then deswelled over the remainder of the test. The $83 \% \mathrm{AA}+\mathrm{SiO}_{2}$ hydrogel had

FIG. 5 Swelling ratio $(Q)$ as a function of immersion time in (a) RO water and (b) pore solution for both hydrogel compositions. Hydrogel particles containing nanosilica are indicated with filled shapes and solid lines. Hydrogel particles without nanosilica are indicated with open shapes and dashed lines.

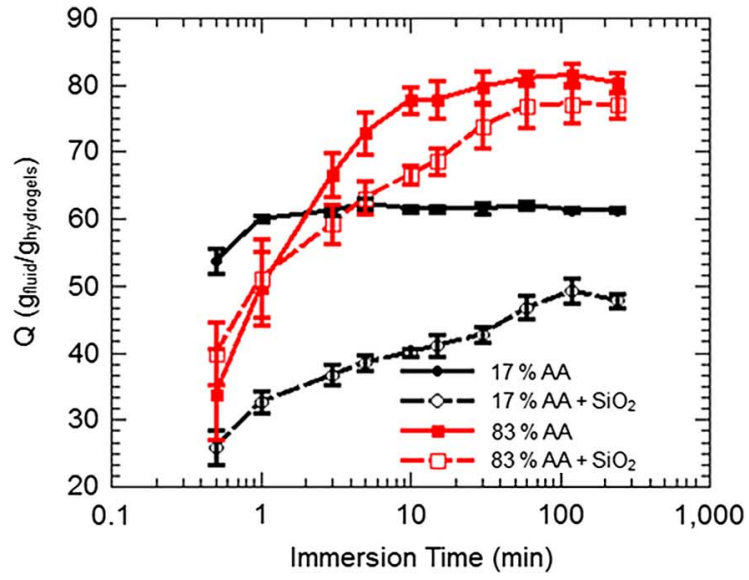

(a)

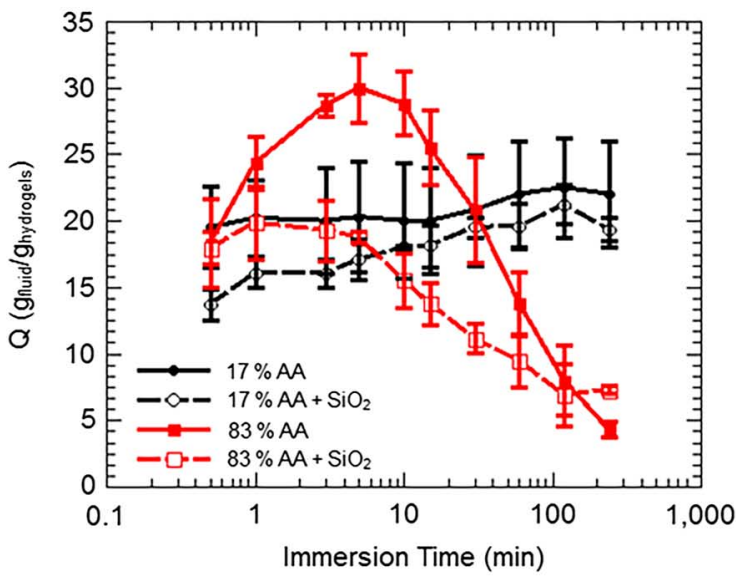

(b) 
equivalent swelling capacity to the $17 \%$ AA hydrogel particles at the beginning of the test, and immediately began to deswell, eventually reaching the same level as the $83 \%$ AA hydrogel at two hours.

\section{BACKSCATTERED ELECTRON MICROSCOPY ON CEMENT PASTES}

All cement paste samples were cured in limewater for 48 hours after an initial 24-hour sealed period. Scanning electron micrographs of cement paste with no hydrogel particles are shown in Fig. 6. Micrographs of cement pastes with hydrogel particles containing no nanosilica are shown in Fig. 7. Micrographs of cement pastes with hydrogel particles containing 8.5 wt.\% of nanosilica are shown in Fig. 8. A 17\% AA hydrogel void with the $\mathrm{CH}$ phase highlighted and indicated with an arrow is shown in Fig. 7a. Remains of the hydrogel particle are visible within the center of the void. Three $83 \%$ AA hydrogel voids are visible in Fig. 7b. Similar hydrogel void microstructures were observed in the cement samples containing hydrogel particles that contained nanosilica. In Fig. 8a, a $17 \%$ $\mathrm{AA}+\mathrm{SiO}_{2}$ hydrogel void is shown, which was found to contain both $\mathrm{CH}$ and $\mathrm{CSH}$ phases. These are indicated with dark blue and light green colors, respectively.

A minimum of 100 hydrogel voids in each cement sample were examined for hydrated product, and a percentage of the total number of voids counted that contained either $\mathrm{CH}$ or $\mathrm{CSH}$ was calculated. These percentages are shown in Fig. 9. It was observed that as the amount of AA in the nanosilica-free hydrogel particles increased from $17 \%$ to $83 \%$ (and AM decreased proportionately), the percentages of voids containing $\mathrm{CH}$ and CSH decreased by $99 \%$ and $75 \%$, respectively.

Fig. 9 also shows that the addition of nanosilica to the hydrogel particles caused the number of voids containing $\mathrm{CSH}$ to increase for both hydrogel particle compositions. For $17 \%$ AA hydrogel particles, a $53 \%$ increase in voids containing CSH was observed with the addition of nanosilica, while a $140 \%$ increase was observed for $83 \%$ AA hydrogel particles upon the addition of nanosilica. Nanosilica caused the number of voids 
FIG. 7 Scanning electron micrographs of cement pastes with (a) $17 \%$ AA and (b) $83 \%$ AA hydrogel particles. Hydrogel voids are indicated with arrows, and the $\mathrm{CH}$ phase within the $17 \%$ AA hydrogel void has been shaded and indicated with an arrow.

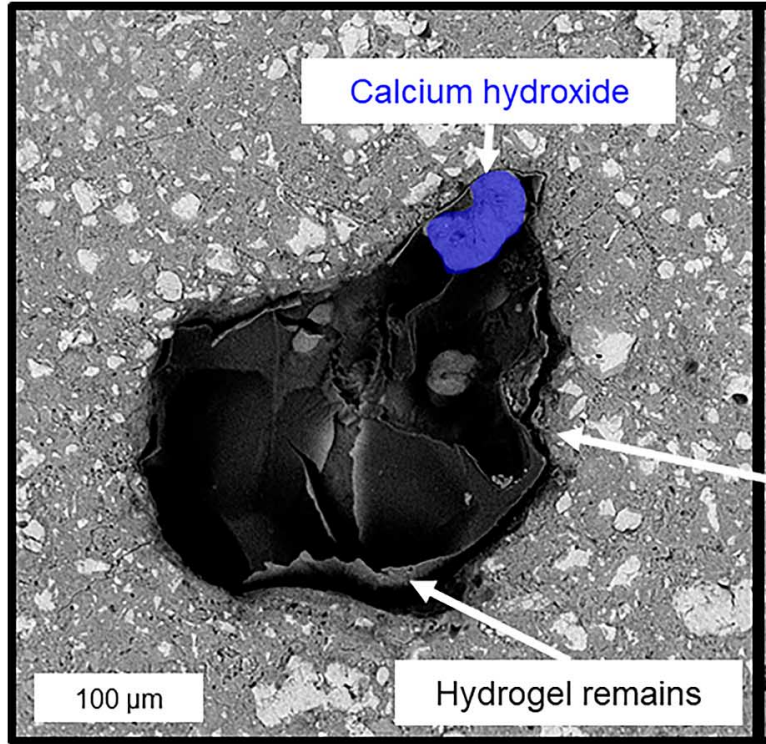

(a)

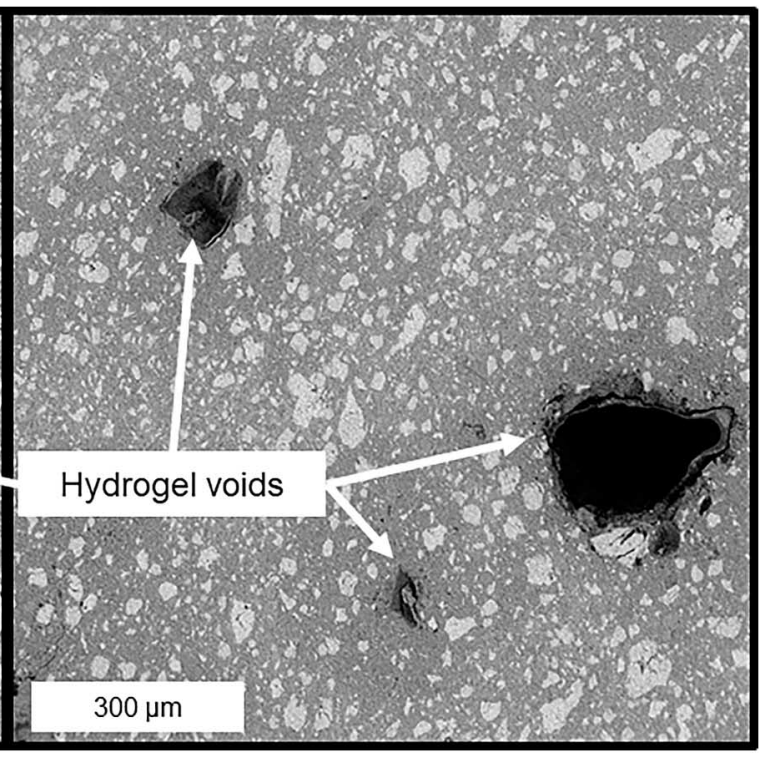

(b)

FIG. 8 Scanning electron micrographs of cement pastes with (a) $17 \% \mathrm{AA}+\mathrm{SiO}_{2}$ and b) $83 \% \mathrm{AA}+\mathrm{SiO}_{2}$ hydrogel particles. $\mathrm{CH}$ and $\mathrm{CSH}$ phases have been highlighted and marked with arrows.

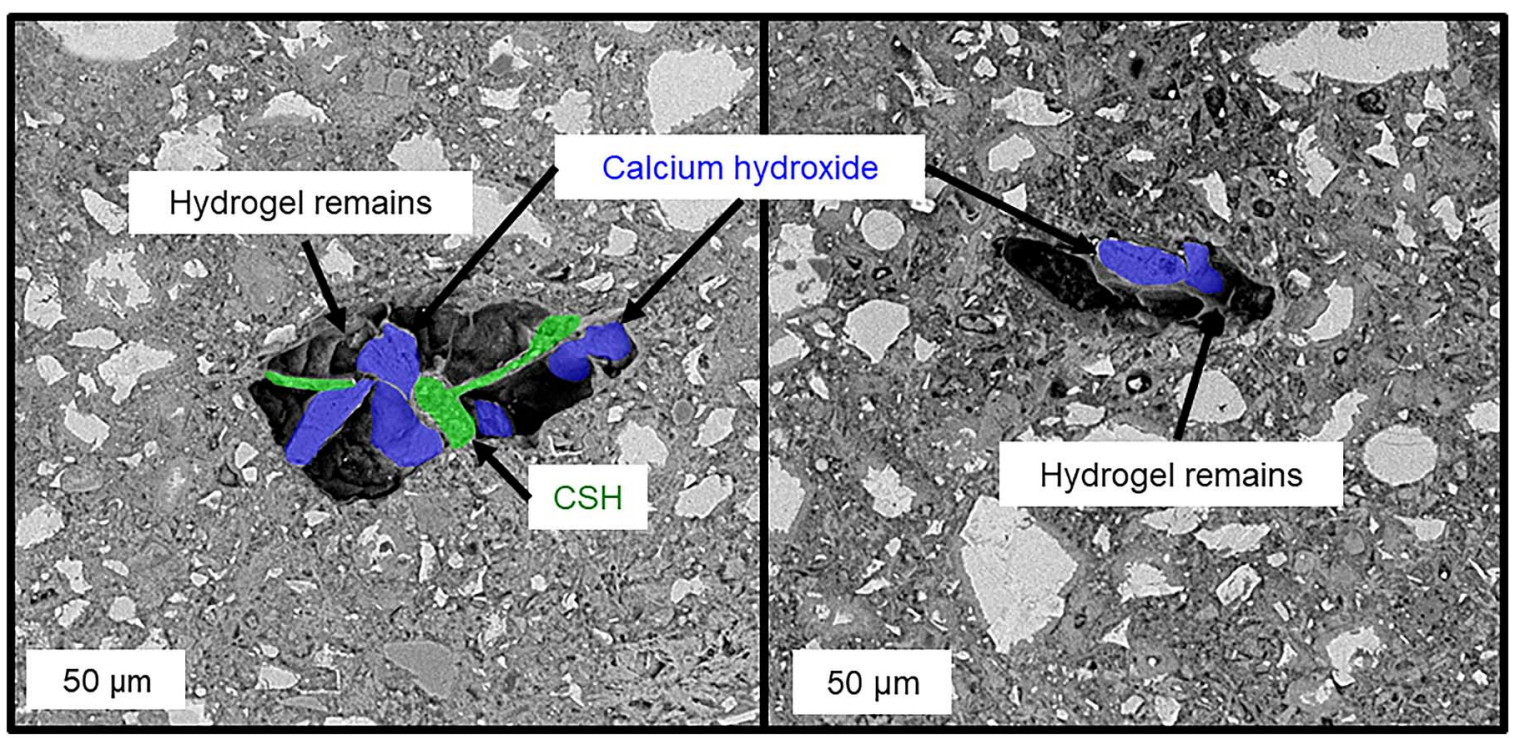

(a)

(b)

containing $\mathrm{CH}$ to increase significantly only for the $83 \%$ AA hydrogel particles, while the percent change in $\mathrm{CH}$ for the $17 \%$ AA hydrogel particles upon the addition of nanosilica was not significant, considering the uncertainties. 
FIG. 9

Percent of all imaged hydrogel voids that contained any hydrated product, shown by gray columns, and only $\mathrm{CH}$ phases, shown with crosshatched columns. Average values are reported immediately above each column.

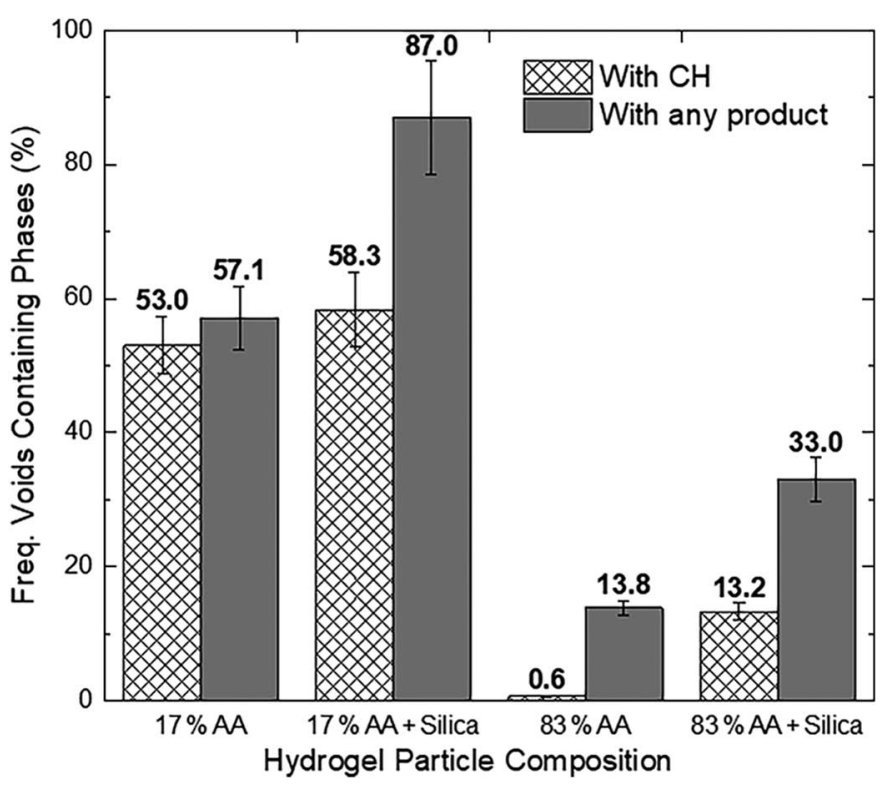

\section{Discussion}

\section{SWELLING PERFORMANCE OF HYDROGEL PARTICLES}

The swelling test results shown in Fig. 5a indicated that the addition of nanosilica significantly reduced the maximum swelling capacity of the $17 \%$ AA hydrogel particles in RO water. Because the nanosilica particles are negatively charged in $\mathrm{RO}$ water, and amide groups have a partial positive charge, the nanosilica may preferentially associate with $\mathrm{AM}$ and thus prevent the hydrogel network from attaining the largest possible expansion during swelling. Since the swelling capacity of the $83 \%$ AA hydrogel particles was not significantly reduced, the nanosilica may not have interfered with the flexibility of the AA chain segments. More investigation is required to understand how exactly nanosilica impacts the polymer chain integrity and polymerization of hydrogel particles.

Markedly different swelling kinetics and capacities were observed for all compositions of hydrogel particles exposed to pore solution, as shown in Fig. 5b, which was expected because of the high concentration of aqueous cations (e.g., sodium, potassium, calcium). It is well-known that positively charged ions (or particles) will electrostatically complex with the polymer network, reduce swelling capacity, and cause deswelling in the case of majority-AA hydrogel particles [53,54,61-63]. The relatively constant swelling ratio displayed by the $17 \%$ AA hydrogel particles suggests that the majority-AM polymer network was resistant to deswelling caused by multivalent cations. However, because of the reduction in swelling capacity, it can be inferred that the majority-AM hydrogel particles were still vulnerable to the electrostatic shielding effects caused by monovalent cations. The addition of nanosilica did not significantly change the long-time (e.g., $4 \mathrm{~h}$ ) swelling response of either hydrogel composition in pore solution, which suggests that any effects the nanosilica had on the polymer networks did not manifest at low swelling ratios. However, the $83 \% \mathrm{AA}+\mathrm{SiO}_{2}$ hydrogel particles did display a reduction in the short-time 
(e.g., 5 minutes) swelling ratios in contrast to the $83 \%$ AA hydrogel particles with no nanosilica. Between the negatively charged AA polymer network and the negatively charged nanosilica particles, electrostatic complexing with multivalent cations may have been able to take place much faster in the $83 \% \mathrm{AA}+\mathrm{SiO}_{2}$ hydrogel particles and thus led to a quicker collapse of the polymer network in contrast to the nanosilica-free particles.

\section{EFFECT OF THE HYDROGEL PARTICLES ON CEMENT MICROSTRUCTURE}

A uniform microstructure with no large pores was observed in the control paste, as shown in Fig. 6. As expected, pastes containing hydrogel particles were observed to have large angular voids, as shown in Figs. 7 and 8. In some of these voids, hydrogel remains were visible within the center portion of the void. Similar microstructures have been recently reported by Farzanian and Ghahremaninezhad [98]. Hydrated product was also observed to be present in the interiors of hydrogel voids, as indicated in Figs. 7a and 8.

From each sample, at least 100 hydrogel voids were imaged and evaluated for the presence of hydrated product. EDX was used to confirm the morphologies of $\mathrm{CH}$ and $\mathrm{CSH}$ phases. A percentage of hydrogel voids containing only $\mathrm{CH}$ or $\mathrm{CH}$ and $\mathrm{CSH}$ (i.e., any product) was calculated, and these results are reported in Fig. 9. There may have been instances in which additional hydrated product formed in areas of hydrogel particle voids that could not be readily examined by the microscope or analyzed with EDX. As such, the results in Fig. 9 were obtained from examining the phase morphologies present at the surface of the hydrogel void.

The results from the void analysis in Fig. 9 indicated that the amount of AM within the hydrogel network strongly influenced whether or not hydrated product formed within the hydrogel void. The majority-AA hydrogel particles had $75 \%$ fewer hydrogel voids containing $\mathrm{CSH}$ and $99 \%$ fewer hydrogel voids containing $\mathrm{CH}$ than the majority-AM hydrogel particles. This is a surprising result, because the negatively charged majority-AA polymer was expected to provide more binding sites for calcium ions and thus potentially cause more $\mathrm{CH}$ to form. However, the fact that majority-AM hydrogel particles are able to retain water for longer periods of time within a cementitious environment, as evidenced by Fig. 5, could suggest that a large, water-filled inclusion is a relatively more favorable environment for $\mathrm{CH}$ formation.

The addition of nanosilica was observed to increase the percentage of hydrogel voids containing $\mathrm{CH}$ and $\mathrm{CSH}$ for both hydrogel compositions (except, notably, in the case of the $\mathrm{CH}$ phase for the $17 \%$ AA hydrogel particles). It was observed that the amount of hydrogel voids containing $\mathrm{CH}$ and $\mathrm{CSH}$ increased by approximately 2,100\% and $140 \%$, respectively, for the $83 \%$ AA hydrogel particles. The amount of hydrogel voids containing CSH increased by $53 \%$ for the $17 \%$ AA hydrogel particles. Between the different compositions of hydrogels with nanosilica, however, there was a $62 \%$ decrease in the amount of hydrogel voids containing CSH and a $78 \%$ decrease in the amount of hydrogel voids containing $\mathrm{CH}$, as the amount of AA increased from $17 \%$ to $83 \%$. This may suggest that the hydrogel composition (in terms of percent AA) is still a major influencing factor on whether or not any hydrated product is able to form within the hydrogel void. This lends further support to the hypothesized retention of water and relative insensitivity to cations of the majority-AM hydrogels for creating a preferential region for hydrated product to form within the cement paste. These results also suggest that the addition of nanosilica may enhance the nucleation of the $\mathrm{CH}$ phase within hydrogels, because of the fact that equal or greater percentages of hydrogel voids containing $\mathrm{CH}$ were seen. Furthermore, the nanosilica may be able to combine with the water and $\mathrm{CH}$ to form an additional $\mathrm{CSH}$ 
phase within the hydrogel particles, given the observed increases in CSH within the voids from hydrogel particles containing nanosilica.

It is worth noting that all cement paste samples were cured in limewater for 48 hours after an initial 24-hour sealed period. The concern may be raised that this additional external water obscures effects that the hydrogel chemistry alone has on cement microstructure. However, the results in Fig. 9 clearly indicate that even with the compensation for this additional water content, the differences between the hydrogel compositions are still apparent.

\section{Conclusions and Implications}

Two different compositions of superabsorbent polymer hydrogel particles were synthesized and combined with nanosilica particles. Swelling capacities and kinetics were evaluated with gravimetric swelling tests. It was observed that nanosilica reduced the maximum swelling capacity of both hydrogel chemistries. The swelling kinetics of $17 \% \mathrm{AA}$ hydrogel particles were not significantly impacted by the addition of silica, but the shorttime swelling capacity of the $83 \%$ AA hydrogel particles was reduced with the addition of nanosilica. These reductions in swelling capacities may have been caused by the negatively charged nanosilica preferentially associating with the amide groups in the majority-AM hydrogel particles, thus restricting the polymer network expansion during swelling. Furthermore, the additional negative charges associated with the nanosilica particles that are confined in the hydrogel network may have led to rapid complexing with cations in pore solution, which dramatically enhanced the deswelling behavior observed in $83 \% \mathrm{AA}$ $+\mathrm{SiO}_{2}$ hydrogel particles. Backscattered microscopy indicated that $17 \%$ AA hydrogel particles resulted in a higher percentage of voids that contained some amount of $\mathrm{CH}$ and CSH phases in cement paste, as compared to the voids created by the $83 \%$ AA hydrogel particles. This effect was enhanced with the addition of nanosilica to the hydrogel particles, and both hydrogel compositions resulted in an even larger percentage of voids containing $\mathrm{CSH}$ with addition of $\mathrm{SiO}_{2}$. In the case of $83 \% \mathrm{AA}+\mathrm{SiO}_{2}$, there was a higher percentage of voids containing $\mathrm{CH}$ as well, although this was not observed for the $17 \%$ $\mathrm{AA}+\mathrm{SiO}_{2}$ hydrogel particles.

These results suggest that the ability of the majority-AM hydrogel particles to retain water for relatively long periods of time may be creating a favorable environment for the formation of $\mathrm{CH}$, as well as providing enough water for further reaction with the nanosilica to form CSH. It is particularly noteworthy that the estimated loading levels of $\mathrm{SiO}_{2}$ in the swollen hydrogel particles are believed to be much less than one percent (by volume), which makes the observed changes in microstructure all the more impressive. Thus, through control of hydrogel particle composition, it may be possible to create an internally cured cement microstructure that is not only less porous because of enhanced curing and a reduced global w/c ratio, but also mechanically stronger and more durable because of the formation of hydrated product within the void space previously occupied by swollen hydrogel particles.

\section{ACKNOWLEDGMENTS}

The authors would like to acknowledge the National Science Foundation award CMMI\#1454360 and the donors of the American Chemical Society Petroleum Research Fund for partial support of this research. Additionally, the authors would like to thank the Lyles School of Civil Engineering at Purdue University for allowing the use of the Charles 
Pankow Concrete Materials Laboratories, Mr. Jerome Nash for his assistance with the zeta potential measurements, and Ms. Raikhan Tokpatayeva for her assistance with the XRD measurements.

\section{References}

[1] Weber, S. and Reinhardt, H. W., "A New Generation of High Performance Concrete: Concrete with Autogenous Curing," Adv. Cem. Based Mater., Vol. 6, No. 2, 1997, pp. 59-68, https://doi.org/10.1016/S1065-7355(97)00009-6

[2] Walraven, J., "High Performance Concrete: A Material with a Large Potential," J. Adv. Concr. Technol., Vol. 7, No. 2, 2009, pp. 145-156, https://doi.org/10.3151/jact.7.145

[3] Habert, G., Arribe, D., Dehove, T., Espinasse, L., and Le Roy, R., "Reducing Environmental Impact by Increasing the Strength of Concrete: Quantification of the Improvement to Concrete Bridges," J. Cleaner Prod., Vol. 35, 2012, pp. 250-262, https://doi.org/10.1016/j.jclepro.2012.05.028

[4] Shi, C., Wu, Z., Xiao, J., Wang, D., Huang, Z., and Fang, Z., "A Review on Ultra High Performance Concrete: Part I. Raw Materials and Mixture Design,” Constr. Build. Mater., Vol. 101, Part 1, 2015, pp. 741-751, https://doi.org/10.1016/j.conbuildmat. 2015.10.088

[5] ACI Committee 231, "ACI 231R-10 Report on Early-Age Cracking: Causes, Measurement, and Mitigation," American Concrete Institute, Farmington Hills, MI, 2010, 46p.

[6] Lura, P., Jensen, O. M., and Weiss, J., "Cracking in Cement Paste Induced by Autogenous Shrinkage,” Mater. Struct., Vol. 42, No. 8, 2009, pp. 1089-1099, https://doi.org/10.1617/s11527-008-9445-Z

[7] Weiss, W. J., Yang, W., and Shah, S. P., "Shrinkage Cracking of Restrained Concrete Slabs," J. Eng. Mech., Vol. 124, No. 7, 1998, pp. 765-774, https://doi.org/10.1061/ (ASCE)0733-9399(1998)124:7(765)

[8] Ghourchian, S., Wyrzykowski, M., Lura, P., Shekarchi, M., and Ahmadi, B., "An Investigation on the Use of Zeolite Aggregates for Internal Curing of Concrete," Constr. Build. Mater., Vol. 40, 2013, pp. 135-144, https://doi.org/10.1016/j. conbuildmat.2012.10.009

[9] Mignon, A., Snoeck, D., Dubruel, P., Van Vlierberghe, S., and De Belie, N., "Crack Mitigation in Concrete: Superabsorbent Polymers as Key to Success?” Materials (Basel), Vol. 10, No. 3, 2017, p. 237, https://doi.org/10.3390/ma10030237

[10] Pourjavadi, A., Fakoorpoor, S. M., Khaloo, A., and Hosseini, P., "Improving the Performance of Cement-Based Composites Containing Superabsorbent Polymers by Utilization of Nano-SiO2 Particles," Mater. Des., Vol. 42, 2012, pp. 94-101, https://doi.org/10.1016/j.matdes.2012.05.030

[11] Bentur, A., Igarashi, S., and Kovler, K., "Prevention of Autogenous Shrinkage in High-Strength Concrete by Internal Curing Using Wet Lightweight Aggregates," Cem. Concr. Res., Vol. 31, No. 11, 2001, pp. 1587-1591, https://doi.org/10.1016/ S0008-8846(01)00608-1

[12] Zhutovsky, S., Kovler, K., and Bentur, A., "Efficiency of Lightweight Aggregates for Internal Curing of High Strength Concrete to Eliminate Autogenous Shrinkage," Mater. Struct., Vol. 35, No. 2, 2002, pp. 97-101, https://doi.org/10.1007/BF02482108

[13] Jensen, O. M. and Lura, P., "Techniques and Materials for Internal Water Curing of Concrete," Mater. Struct., Vol. 39, No. 9, 2006, pp. 817-825, https://doi.org/10.1617/ s11527-006-9136-6

[14] Jensen, O. M. and Hansen, P. F., "Water-Entrained Cement-Based Materials: I. Principles and Theoretical Background," Cem. Concr. Res., Vol. 31, No. 4, 2001, pp. 647-654, https://doi.org/10.1016/S0008-8846(01)00463-X

[15] Jensen, O. M. and Hansen, P. F., "Water-Entrained Cement-Based Materials : II. Experimental Observations," Cem. Concr. Res., Vol. 32, No. 6, 2002, pp. 973-978, https://doi.org/10.1016/S0008-8846(02)00737-8 
[16] Wyrzykowski, M., Lura, P., Pesavento, F., and Gawin, D., "Modeling of Water Migration during Internal Curing with Superabsorbent Polymers," J. Mater. Civ. Eng., Vol. 24, No. 8, 2012, pp. 1006-1016, https://doi.org/10.1061/(ASCE)MT. 1943-5533.0000448

[17] Schröfl, C., Mechtcherine, V., and Gorges, M., "Relation between the Molecular Structure and the Efficiency of Superabsorbent Polymers (SAP) as Concrete Admixture to Mitigate Autogenous Shrinkage," Cem. Concr. Res., Vol. 42, No. 6, 2012, pp. 865-873, https://doi.org/10.1016/j.cemconres.2012.03.011

[18] Bentz, D. P. and Weiss, W. J., "Internal Curing: A 2010 State-of-the-Art Review," NIST Internal Report 7765, National Institute of Standards and Technology, Gaithersburg, MD, 2011, 82p.

[19] Assmann, A. and Reinhardt, H. W., "Tensile Creep and Shrinkage of SAP Modified Concrete," Cem. Concr. Res., Vol. 58, 2014, pp. 179-185, https://doi.org/10.1016/j. cemconres.2014.01.014

[20] Kong, X., Zhang, Z., and Lu, Z., "Effect of Pre-soaked Superabsorbent Polymer on Shrinkage of High-Strength Concrete," Mater. Struct., Vol. 48, No. 9, 2015, pp. 2741-2758, https://doi.org/10.1617/s11527-014-0351-2

[21] Snoeck, D., Jensen, O. M., and De Belie, N., "The Influence of Superabsorbent Polymers on the Autogenous Shrinkage Properties of Cement Pastes with Supplementary Cementitious Materials," Cem. Concr. Res., Vol. 74, 2015, pp. 59-67, https://doi.org/10.1016/j.cemconres.2015.03.020

[22] Hasholt, M. T., Jensen, O. M., Kovler, K., and Zhutovsky, S., "Can Superabsorent Polymers Mitigate Autogenous Shrinkage of Internally Cured Concrete without Compromising the Strength?" Constr. Build. Mater., Vol. 31, 2012, pp. 226-230, https://doi.org/10.1016/j.conbuildmat.2011.12.062

[23] Mechtcherine, V., Gorges, M., Schroefl, C., Assmann, A., Brameshuber, W., Ribeiro, A. B., Cusson, D., Custódio, J., da Silva, E. F., Ichimiya, K., Igarashi, S., Klemm, A., Kovler, K., de Mendonça Lopes, A. N., Lura, P., Nguyen, V. T., Reinhardt, H.-W., Filho, R. D. T., Weiss, J., Wyrzykowski, M., Ye, G., and Zhutovsky, S., "Effect of Internal Curing by Using Superabsorbent Polymers (SAP) on Autogenous Shrinkage and Other Properties of a High-Performance Fine-Grained Concrete: Results of a RILEM Round-Robin Test," Mater. Struct., Vol. 47, No. 3, 2014, pp. 541-562, https://doi.org/10.1617/s11527-013-0078-5

[24] Justs, J., Wyrzykowski, M., Bajare, D., and Lura, P., "Internal Curing by Superabsorbent Polymers in Ultra-High Performance Concrete," Cem. Concr. Res., Vol. 76, 2015, pp. 82-90, https://doi.org/10.1016/j.cemconres.2015.05.005

[25] Shen, D., Jiang, J., Zhang, M., Yao, P., and Jiang, G., "Tensile Creep and Cracking Potential of High Performance Concrete Internally Cured with Super Absorbent Polymers at Early Age," Constr. Build. Mater., Vol. 165, 2018, pp. 451-461, https:// doi.org/10.1016/j.conbuildmat.2017.12.136

[26] Radlinska, A., Rajabipour, F., Bucher, B., Henkensiefken, R., Sant, G., and Weiss, J., "Shrinkage Mitigation Strategies in Cementitious Systems: A Closer Look at Differences in Sealed and Unsealed Behavior," Transp. Res. Rec., Vol. 2070, 2008, pp. 59-67, https://doi.org/10.3141/2070-08

[27] Mignon, A., Snoeck, D., Schaubroeck, D., Luickx, N., Dubruel, P., Van Vlierberghe, S., and De Belie, N., "pH-Responsive Superabsorbent Polymers: A Pathway to SelfHealing of Mortar," React. Funct. Polym., Vol. 93, 2015, pp. 68-76, https://doi.org/ 10.1016/j.reactfunctpolym.2015.06.003

[28] Lee, H. X. D., Wong, H. S., and Buenfeld, N. R., "Potential of Superabsorbent Polymer for Self-Sealing Cracks in Concrete," Adv. Appl. Ceram., Vol. 109, No. 5, 2010, pp. 296-302, https://doi.org/10.1179/174367609X459559

[29] Laustsen, S., Hasholt, M. T., and Jensen, O. M., "Void Structure of Concrete with Superabsorbent Polymers and Its Relation to Frost Resistance of Concrete," Mater. Struct., Vol. 48, Nos. 1-2, 2015, pp. 357-368, https://doi.org/10.1617/s11527013-0188-0 
[30] Hasholt, M. T., Jensen, O. M., and Laustsen, S., "Superabsorbent Polymers as a Means of Improving Frost Resistance of Concrete," Adv. Civ. Eng. Mater., Vol. 4, No. 1, 2015, pp. 237-256, https://doi.org/10.1520/ACEM20150012

[31] Mönnig, S. and Lura, P., "Superabsorbent Polymers-An Additive to Increase the Freeze-Thaw Resistance of High Strength Concrete," Advances in Construction Materials 2007, Springer Berlin Heidelberg, Berlin, Germany, 2007, pp. 351-358, https://doi.org/10.1007/978-3-540-72448-3_35

[32] Laustsen, S., Hasholt, M. T., and Jensen, O. M., "A New Technology for AirEntrainment of Concrete," presented at the First International Conference on Microstructure Related Durability of Cementitious Composites, Nanjing, China, Oct. 13-15, 2008, RILEM Publications, Paris, France, pp. 1223-1230.

[33] Reinhardt, H. W., Assmann, A., and Mönnig, S., "Superabsorbent Polymers (SAPS) An Admixture to Increase the Durability of Concrete," presented at the First International Conference on Microstructure Related Durability of Cementitious Composites, Nanjing, China, Oct. 13-15, 2008, RILEM Publications, Paris, France, pp. 313-322.

[34] Mechtcherine, V., Schröfl, C., Wyrzykowski, M., Gorges, M., Lura, P., Cusson, D., Margeson, J., De Belie, N., Snoeck, D., Ichimiya, K., Igarashi, S.-I., Falikman, V., Friedrich, S., Bokern, J., Kara, P., Marciniak, A., Reinhardt, H.-W., Sippel, S., Ribeiro, A. B., Custódio, J., Ye, G., Dong, H., and Weiss, J., "Effect of Superabsorbent Polymers (SAP) on the Freeze-Thaw Resistance of Concrete: Results of a RILEM Interlaboratory Study," Mater. Struct., Vol. 50, No. 1, 2017, pp. 1-19, https://doi.org/10.1617/s11527-016-0868-7

[35] Liu, J., Shi, C., Ma, X., Khayat, K. H., Zhang, J., and Wang, D., "An Overview on the Effect of Internal Curing on Shrinkage of High Performance Cement-Based Materials," Constr. Build. Mater., Vol. 146, 2017, pp. 702-712, https://doi.org/10. 1016/j.conbuildmat.2017.04.154

[36] Jensen, O. M., Lura, P., and Kovler, K., "Material and Methods for Internal Curing," Internal Curing of Contrete - State-of-the-Art Report of RILEM Technical Committee 196-ICC, K. Kovler and O. Jensen, Eds., RILEM Publications SARL, Paris, France, 2007, pp. 45-55.

[37] Hou, P. K., Kawashima, S., Wang, K. J., Corr, D. J., Qian, J. S., and Shah, S. P., "Effects of Colloidal Nanosilica on Rheological and Mechanical Properties of Fly Ash-Cement Mortar," Cem. Concr. Compos., Vol. 35, No. 1, 2013, pp. 12-22, https://doi.org/10. 1016/j.cemconcomp.2012.08.027

[38] Setayesh Gar, P., Suresh, N., and Bindiganavile, V., "Sugar Cane Bagasse Ash as a Pozzolanic Admixture in Concrete for Resistance to Sustained Elevated Temperatures," Constr. Build. Mater., Vol. 153, 2017, pp. 929-936, https://doi. org/10.1016/j.conbuildmat.2017.07.107

[39] Salas, A., Delvasto, S., de Gutierrez, R. M., and Lange, D., "Comparison of Two Processes for Treating Rice Husk Ash for Use in High Performance Concrete," Cem. Concr. Res., Vol. 39, No. 9, 2009, pp. 773-778, https://doi.org/10.1016/j. cemconres.2009.05.006

[40] Madani, H., Bagheri, A., and Parhizkar, T., "The Pozzolanic Reactivity of Monodispersed Nanosilica Hydrosols and Their Influence on the Hydration Characteristics of Portland Cement," Cem. Concr. Res., Vol. 42, No. 12, 2012, pp. 1563-1570, https://doi.org/10.1016/j.cemconres.2012.09.004

[41] Berra, M., Carassiti, F., Mangialardi, T., Paolini, A. E., and Sebastiani, M., "Effects of Nanosilica Addition on Workability and Compressive Strength of Portland Cement Pastes," Constr. Build. Mater., Vol. 35, 2012, pp. 666-675, https://doi.org/10.1016/j. conbuildmat.2012.04.132

[42] Björnström, J., Martinelli, A., Matic, A., Börjesson, L., and Panas, I., “Accelerating Effects of Colloidal Nano-Silica for Beneficial Calcium-Silicate-Hydrate Formation in Cement," Chem. Phys. Lett., Vol. 392, Nos. 1-3, 2004, pp. 242-248, https://doi. org/10.1016/j.cplett.2004.05.071 
[43] Yu, R., Spiesz, P., and Brouwers, H. J. H., "Effect of Nano-Silica on the Hydration and Microstructure Development of Ultra-High Performance Concrete (UHPC) with a Low Binder Amount," Constr. Build. Mater., Vol. 65, 2014, pp. 140-150, https://doi. org/10.1016/j.conbuildmat.2014.04.063

[44] Van, V. T. A., Rößler, C., Bui, D. D., and Ludwig, H. M., "Rice Husk Ash as Both Pozzolanic Admixture and Internal Curing Agent in Ultra-High Performance Concrete," Cem. Concr. Compos., Vol. 53, 2014, pp. 270-278, https://doi.org/10. 1016/j.cemconcomp.2014.07.015

[45] Nie, S., Hu, S., Wang, F., Hu, C., Li, X., and Zhu, Y., "Pozzolanic Reaction of Lightweight Fine Aggregate and Its Influence on the Hydration of Cement," Constr. Build. Mater., Vol. 153, 2017, pp. 165-173, https://doi.org/10.1016/j. conbuildmat.2017.07.111

[46] Adewunmi, A. A., Ismail, S., Owolabi, T. O., Sultan, A. S., Olatunji, S. O., and Ahmad, Z., "Modeling the Thermal Behavior of Coal Fly Ash Based Polymer Gel System for Water Reduction in Oil and Gas Wells," J. Pet. Sci. Eng., Vol. 157, 2017, pp. 430-440, https://doi.org/10.1016/j.petrol.2017.07.019

[47] Cândido, J. D. S., Pereira, A. G. B., Fajardo, A. R., Ricardo, N. M. P. S., Feitosa, J. P. A., Muniz, E. C., and Rodrigues, F. H. A., "Poly(Acrylamide-Co-Acrylate)/Rice Husk Ash Hydrogel Composites. II. Temperature Effect on Rice Husk Ash Obtention," Composites Part B, Vol. 51, 2013, pp. 246-253, https://doi.org/10.1016/j. compositesb.2013.03.027

[48] Friedrich, S., "Superabsorbent Polymers (SAP)," Application of Super Absorbent Polymers (SAP) in Concrete Construction, RILEM State-of-the-Art Reports Vol. 2, Springer Dordrecht, Dordrecht, the Netherlands, 2012, pp. 13-19, https://doi.org/ 10.1007/978-94-007-2733-5_3

[49] Mechtcherine, V., "Use of Superabsorbent Polymers (SAP) as Concrete Additive," RILEM Tech. Lett., Vol. 1, 2016, pp. 81-87, https://doi.org/10.21809/rilemtechlett. 2016.18

[50] Dang, J., Zhao, J., and Du, Z., "Effect of Superabsorbent Polymer on the Properties of Concrete," Polymers, Vol. 9, No. 12, 2017, pp. 672, https://doi.org/10.3390/ polym 9120672

[51] Rodríguez de Sensale, G. and Goncalves, A. F., "Effects of Fine LWA and SAP as Internal Water Curing Agents," Int. J. Concr. Struct. Mater., Vol. 8, No. 3, 2014, pp. 229-238, https://doi.org/10.1007/s40069-014-0076-1

[52] Beushausen, H., Gillmer, M., and Alexander, M., "The Influence of Superabsorbent Polymers on Strength and Durability Properties of Blended Cement Mortars," Cem. Concr. Compos., Vol. 52, 2014, pp. 73-80, https://doi.org/10.1016/j.cemconcomp. 2014.03.008

[53] Kelly, S. L., Krafcik, M. J., and Erk, K. A., "Synthesis and Characterization of Superabsorbent Polymer Hydrogels Used as Internal Curing Agents: Impact of Particle Shape on Mortar Compressive Strength," presented at the 16th International Congress of Polymers in Concrete 2018 (ICPIC), Washington, DC, April 29-May 1, 2018, Springer Cham, Cham, Switzerland, pp. 91-97.

[54] Kelly, S. L., Inverse Suspension Polymerization of Superabsorbent Polymer (SAP) Hydrogels for Internally Cured Concrete, M.S. Thesis, Purdue University, West Lafayette, IN, 2017.

[55] Charman, W. N., Christy, D. P., Geunin, E. P., and Monkhouse, D. C., "Interaction between Calcium, a Model Divalent Cation, and a Range of Poly (Acrylic Acid) Resins as a Function of Solution pH," Drug Dev. Ind. Pharm., Vol. 17, No. 2, 2008, pp. 271-280, https://doi.org/10.3109/03639049109043824

[56] Horkay, F., Tasaki, I., and Basser, P. J., "Osmotic Swelling of Polyacrylate Hydrogels in Physiological Salt Solutions,” Biomacromolecules, Vol. 1, No. 1, 2000, pp. 84-90, https://doi.org/10.1021/bm9905031

[57] Krafcik, M. J., Macke, N. D., and Erk, K. A., "Improved Concrete Materials with Hydrogel-Based Internal Curing Agents," Gels, Vol. 3, No. 4, 2017, p. 46, https:// doi.org/10.3390/gels3040046 
[58] Lapitsky, Y. and Kaler, E. W., "Formation of Surfactant and Polyelectrolyte Gel Particles in Aqueous Solutions," Colloids Surf., A, Vol. 250, Nos. 1-3, 2004, pp. 179-187, https://doi.org/10.1016/j.colsurfa.2004.05.028

[59] Huang, Y., Lawrence, P. G., and Lapitsky, Y., "Self-Assembly of Stiff, Adhesive and Self-Healing Gels from Common Polyelectrolytes," Langmuir, Vol. 30, No. 26, 2014, pp. 7771-7777, https://doi.org/10.1021/la404606y

[60] Flory, P. J., Principles of Polymer Chemistry, Cornell University Press, Ithaca, NY, 1953, 688p.

[61] Horkay, F., Tasaki, I., and Basser, P. J., "Effect of Monovalent-Divalent Cation Exchange on the Swelling of Polyacrylate Hydrogels in Physiological Salt Solutions," Biomacromolecules, Vol. 2, No. 1, 2001, pp. 195-199, https://doi.org/10. 1021/bm0056153

[62] Zhu, Q., Barney, C. W., and Erk, K. A., "Effect of Ionic Crosslinking on the Swelling and Mechanical Response of Model Superabsorbent Polymer Hydrogels for Internally Cured Concrete," Mater. Struct., Vol. 48, No. 7, 2015, pp. 2261-2276, https://doi.org/10.1617/s11527-014-0308-5

[63] Krafcik, M. J. and Erk, K. A., "Characterization of Superabsorbent Poly(SodiumAcrylate Acrylamide) Hydrogels and Influence of Chemical Structure on Internally Cured Mortar,” Mater. Struct., Vol. 49, No. 11, 2016, pp. 4765-4778, https://doi.org/10.1617/s11527-016-0823-7

[64] Tabares Tamayo, J. D., “The Influence of Alkalinity of Portland Cement on the Absorption Characteristics of Superabsorbent Polymers (SAP) for Use in Internally Cured Concrete," M.S. Thesis, Purdue University, West Lafayette, IN, 2016.

[65] Esteves, L. P., Superabsorbent Polymers: On Their Interaction with Water and Pore Fluid, " Cem. Concr. Compos., Vol. 33, No. 7, 2011, pp. 717-724, https://doi.org/10. 1016/j.cemconcomp.2011.04.006

[66] Mechtcherine, V., Snoeck, D., Schröfl, C., De Belie, N., Klemm, A. J., Ichimiya, K., Moon, J., Wyrzykowski, M., Lura, P., Toropovs, N., Assmann, A., Igarashi, S.-I., De La Varga, I., Almeida, F. C. R., Erk, K., Bettencourt Ribeiro, A., Custódio, J., Reinhardt, H. W., and Falikman, V., "Testing Superabsorbent Polymer (SAP) Sorption Properties Prior to Implementation in Concrete: Results of a RILEM Round-Robin Test," Mater. Struct., Vol. 51, No. 1, 2018, pp. 1-16, https:/doi.org/ 10.1617/s11527-018-1149-4

[67] Rodríguez de Sensale, G., "Strength Development of Concrete with Rice-Husk Ash," Cem. Concr. Compos., Vol. 28, No. 2, 2006, pp. 158-160, https://doi.org/10.1016/ j.cemconcomp.2005.09.005

[68] Malhotra, V. M., Supplementary Cementing Materials for Concrete, Energy, Mines, and Resources Canada, Canada Centre for Mineral and Energy Technology, Ottawa, Canada, 1987, 428p.

[69] Ramachandran, V. S., Concrete Admixtures Handbook: Properties, Science, and Technology, Noyes Publications, Park Ridge, NJ, 1984, 626p.

[70] Wu, X., Jiang, W., and Roy, D. M., "Early Activation and Properties of Slag Cement," Cem. Concr. Res., Vol. 20, No. 6, 1990, pp. 961-974, https://doi.org/10.1016/00088846(90)90060-B

[71] Wong, H. S. and Razak, H. A., "Efficiency of Calcined Kaolin and Silica Fume as Cement Replacement Material for Strength Performance," Cem. Concr. Res., Vol. 35, No. 4, 2005, pp. 696-702, https://doi.org/10.1016/j.cemconres.2004.05.051

[72] Siddique, R. and Khan, M. I., Supplementary Cementing Materials, Springer Berlin Heidelberg, Berlin, Germany, 2011, 288p.

[73] Espinoza-Hijazin, G., Paul, Á., and Lopez, M., "Concrete Containing Natural Pozzolans: New Challenges for Internal Curing," J. Mater. Civ. Eng., Vol. 24, No. 8, 2012, pp. 981-988, https://doi.org/10.1061/(ASCE)MT.1943-5533.0000421

[74] Mehta, P. K. and Gjørv, O. E., "Properties of Portland Cement Concrete Containing Fly Ash and Condensed Silica-Fume," Cem. Concr. Res., Vol. 12, No. 5, 1982, pp. 587-595, https://doi.org/10.1016/0008-8846(82)90019-9 
[75] Shannag, M. J., "High Strength Concrete Containing Natural Pozzolan and Silica Fume," Cem. Concr. Compos., Vol. 22, No. 6, 2000, pp. 399-406, https://doi.org/ 10.1016/S0958-9465(00)00037-8

[76] Ghafari, E., Costa, H., Júlio, E., Portugal, A., and Durães, L., "The Effect of Nanosilica Addition on Flowability, Strength and Transport Properties of Ultra High Performance Concrete," Mater. Des., Vol. 59, 2014, pp. 1-9, https://doi.org/10. 1016/j.matdes.2014.02.051

[77] Mazloom, M., Ramezanianpour, A. A., and Brooks, J. J., "Effect of Silica Fume on Mechanical Properties of High-Strength Concrete," Cem. Concr. Compos., Vol. 26, No. 4, 2004, pp. 347-357, https://doi.org/10.1016/S0958-9465(03)00017-9

[78] Alshamsi, A. M., Sabouni, A. R., and Bushlaibi, A. H., "Influence of Set-Retarding Superplasticisers and Microsilica on Setting Times of Pastes at Various Temperatures," Cem. Concr. Res., Vol. 23, No. 3, 1993, pp. 592-598, https://doi. org/10.1016/0008-8846(93)90009-X

[79] Mostafa, N. Y., Mohsen, Q., El-Hemaly, S. A. S., El-Korashy, S. A., and Brown, P. W., "High Replacements of Reactive Pozzolan in Blended Cements: Microstructure and Mechanical Properties," Cem. Concr. Compos., Vol. 32, No. 5, 2010, pp. 386-391, https://doi.org/10.1016/j.cemconcomp.2010.02.003

[80] Nili, M. and Ehsani, A., "Investigating the Effect of the Cement Paste and Transition Zone on Strength Development of Concrete Containing Nanosilica and Silica Fume," Mater. Des., Vol. 75, 2015, pp. 174-183, https://doi.org/10.1016/j.matdes.2015.03.024

[81] Lowke, D. and Gehlen, C., "The Zeta Potential of Cement and Additions in Cementitious Suspensions with High Solid Fraction," Cem. Concr. Res., Vol. 95, 2017, pp. 195-204, https://doi.org/10.1016/j.cemconres.2017.02.016

[82] Xu, R., "Progress in Nanoparticles Characterization: Sizing and Zeta Potential Measurement," Particuology, Vol. 6, No. 2, 2008, pp. 112-115, https://doi.org/10. 1016/j.partic.2007.12.002

[83] Elochukwu, H., Gholami, R., and Sham Dol, S., "An Approach to Improve the Cuttings Carrying Capacity of Nanosilica Based Muds," J. Pet. Sci. Eng., Vol. 152, 2017, pp. 309-316, https://doi.org/10.1016/j.petrol.2017.03.008

[84] Kim, K. M., Kim, H. M., Lee, W. J., Lee, C. W., Kim, T., Lee, J. K., Jeong, J., Paek, S. M., and Oh, J. M., "Surface Treatment of Silica Nanoparticles for Stable and ChargeControlled Colloidal Silica," Int. J. Nanomedicine, Vol. 9, Suppl. 2, 2014, pp. 29-40.

[85] Li, H., Xiao, H. G., Yuan, J., and Ou, J., "Microstructure of Cement Mortar with Nano-Particles," Composites Part B, Vol. 35, No. 2, 2004, pp. 185-189, https:// doi.org/10.1016/S1359-8368(03)00052-0

[86] Jo, B. W., Kim, C. H., and Lim, J. H., "Characteristics of Cement Mortar with NanoSiO2 Particles," ACI Mater. J., Vol. 104, No. 4, 2007, pp. 404-407.

[87] Ji, T., "Preliminary Study on the Water Permeability and Microstructure of Concrete Incorporating Nano-SiO2," Cem. Concr. Res., Vol. 35, No. 10, 2005, pp. 1943-1947, https://doi.org/10.1016/j.cemconres.2005.07.004

[88] Sanchez, F. and Sobolev, K., "Nanotechnology in Concrete - A Review," Constr. Build. Mater., Vol. 24, No. 11, 2010, pp. 2060-2071, https://doi.org/10.1016/j.conbuildmat. 2010.03.014

[89] Merget, R., Bauer, T., Küpper, H., Philippou, S., Bauer, H., Breitstadt, T., and Bruening, T., "Health Hazards Due to the Inhalation of Amorphous Silica," Arch. Toxicol., Vol. 75, Nos. 11-12, 2002, pp. 625-634, https://doi.org/10.1007/ s002040100266

[90] Maas, A. J., Ideker, J. H., and Juenger, M. C. G., "Alkali Silica Reactivity of Agglomerated Silica Fume,” Cem. Concr. Res., Vol. 37, No. 2, 2007, pp. 166-174, https://doi.org/10.1016/j.cemconres.2006.10.011

[91] Duchesne, J. and Bérubé, M. A., "The Effectiveness of Supplementary Cementing Materials in Suppressing Expansion Due to ASR: Another Look at the Reaction Mechanisms Part 2: Pore Solution Chemistry," Cem. Concr. Res., Vol. 24, No. 2, 1994, pp. 221-230, https://doi.org/10.1016/0008-8846(94)90047-7 
[92] Ichikawa, T., "Alkali-Silica Reaction, Pessimum Effects and Pozzolanic Effect," Cem. Concr. Res., Vol. 39, No. 8, 2009, pp. 716-726, https://doi.org/10.1016/j.cemconres. 2009.06.004

[93] Kim, S., Thiessen, P. A., Bolton, E. E., Chen, J., Fu, G., Gindulyte, A., Han, L., He, J., He, S., Shoemaker, A., Wang, J., Yu, B., Zhang, J., and Bryant, S. H., "PubChem Substance and Compound Databases," Nucleic Acids Res., Vol 44, No. D1, 2016, D1202-D1213, https://doi.org/10.1093/nar/gkv951

[94] Rubinstein, M. and Colby, R. H., Polymer Physics, Oxford University Press, New York, NY, 2003, 454p.

[95] ASTM C150-17, Standard Specification for Portland Cement, ASTM International, West Conshohocken, PA, 2017, www.astm.org

[96] Chisholm, J., "Comparison of Quartz Standards for X-Ray Diffraction Analysis: HSE A9950 (Sikron F600) and NIST SRM 1878,” Ann. Occup. Hyg., Vol. 49, No. 4, 2005, pp. 351-358.

[97] Mechtcherine, V., Secrieru, E., and Schröfl, C., "Effect of Superabsorbent Polymers (SAPs) on Rheological Properties of Fresh Cement-Based Mortars - Development of Yield Stress and Plastic Viscosity over Time," Cem. Concr. Res., Vol. 67, 2015, pp. 52-65, https://doi.org/10.1016/j.cemconres.2014.07.003

[98] Farzanian, K. and Ghahremaninezhad, A., "The Effect of the Capillary Forces on the Desorption of Hydrogels in Contact with a Porous Cementitious Material," Mater. Struct., Vol. 50, No. 5, 2017, pp. 1-15, https://doi.org/10.1617/s11527-017-1068-9 